\title{
HYBRID ANKLE PROSTHESIS IN A CASE OF POST-TRAUMATIC AVASCULAR NECROSIS OF THE TALUS
}

Ricardo Jorge Gomes de Sousa', Ricardo Pedro Ferreira Rodrigues Pinto', Marta Maria Teixeira de Oliveira Massada', Manuel Alexandre Negrais Pinho Gonçalves Pereira', José Muras Geada², Isabel Maria Gonçalves Costa ${ }^{3}$

\section{ABSTRACT}

Talus fractures often lead to late post-traumatic arthrosis. In such cases, the use of latest generation, cementless prostheses has been hindered by the presence of avascular necrosis. We report the case of a 65-year-old patient who presented four years after a talus neck fracture. He had painful ankle arthrosis (AOFAS ankle-hindfoot score 19) and avascular necrosis, with collapse of the entire talar dome. Given the extent of the necrosis, it was decided to cement the talus prosthetic component. One year after the surgery, the patient shows good clinical and radiological results (AOFAS ankle-hindfoot score 87) and is satisfied with the procedure. We are not aware of any similar reports in the literature.

Keywords - Ankle Joint; Talus; Osteonecrosis; Cementation

\section{INTRODUCTION}

Fractures of the body and neck of the talus are infrequent lesions but have the potential to produce functional sequelae over the long term, for which prevention is not always possible. The prevalence of post-traumatic arthrosis is between 35 and $100 \%$, and both the ankle and the subtalar joint are affected ${ }^{(1-3)}$. In a series that we followed, ankle arthrosis was present in $40 \%$ of the cases after five years $^{(4)}$.

Avascular necrosis is a characteristic complication after fractures of the body and neck of the talus and it results in interruption of the blood irrigation coming from the sinus and tarsal tunnel at the talar neck. Its prevalence is related to the initial degree of deviation $^{(5)}$.

The development of total ankle arthroplasty started in the $1970 \mathrm{~s}^{(6)}$. The original models were cemented and highly constrictive, and so they sometimes failed.
New generations were developed and, today, the ankle prostheses most commonly used share the common characteristics that all of them have a porous coating so as to favor bone interdigitation: not depending on cementation for fixation but, rather, on osseointegration $^{(6)}$. Thus, avascular necrosis of the talus has classically been considered to be a contraindication for performing total ankle arthroplasty ${ }^{(7)}$.

We report on the result, after one year of follow-up, from implantation of a total ankle prosthesis in a patient with avascular necrosis and collapse of the entire talar dome. The prosthesis used was the Salto Total Ankle Prosthesis (Tornier, France), which was implanted using cementation to fix the talar component.

\section{CASE REPORT}

A 65-year-old man presented with a prolonged history of pain, with progressive worsening and rigi-

\footnotetext{
1 - Resident in the Orthopedics Department - Hospital de Santo António - Porto - Portugal.

2 - Attending Physician in the Orthopedics Department - Hospital de Santo António - Porto - Portugal.

3 - Hospital Attending Physician specialist in Orthopedics - Orthopedics Department - Hospital de Santo António - Porto - Portugal
}

Work performed at the Orthopedics Service, Hospital de Santo António, Hospital Center of Porto, Porto, Portugal.

Correspondence: Serviço de Ortopedia do Hospital de Santo António - Centro Hospitalar do Porto - Largo do Professor Abel Salazar - 4099-001 - Porto, Portugal E-mail: ricardojgsousa@gmail.com

Work received for publication: February 2, 2010; accepted for publication: August 23, 2010. 
dity of the left ankle that had obliged him to use two forearm crutches over the last two years. He had the antecedent of an aviation accident four years earlier that resulted in a Hawkins type II fracture of the talar neck. That injury was treated surgically with open reduction and osteosynthesis, using two cancellous bone screws (6.5) by means of an anteromedial approach. Figure 1 shows the initial radiograph and the postoperative control.

The clinical assessment revealed that the flexion-extension range of motion of the ankle was limited, with an extremely low score of 19 on the hindfoot and ankle scale of the American Orthopedic Foot and Ankle Society (AOFAS). The radiographic evaluation revealed signs of post-traumatic arthrosis of the left ankle and almost $100 \%$ collapse of the talar dome, secondary to avascular necrosis (Figure 2). Despite the radiographically visible degenerative abnormalities in the subtalar joint, the patient did not have any pain in inversion-eversion movements of the hindfoot.

Ankle arthroplasty was performed through an extensile anterior approach, in accordance with the original technique for the implant chosen. This consisted of a custom-made talar component prepared for cementation. A cutting guide for the talar dome was used to determine the cutting level, and we decided not to extract the lower cancellous bone screw, since this would not interfere with the positioning of the implant. Cement was used to fill in the bone defects, as well as to achieve fixation of the talar component. Both the surgical procedure and the postoperative period were free from intercurrences.

At the most recent follow-up consultation (12

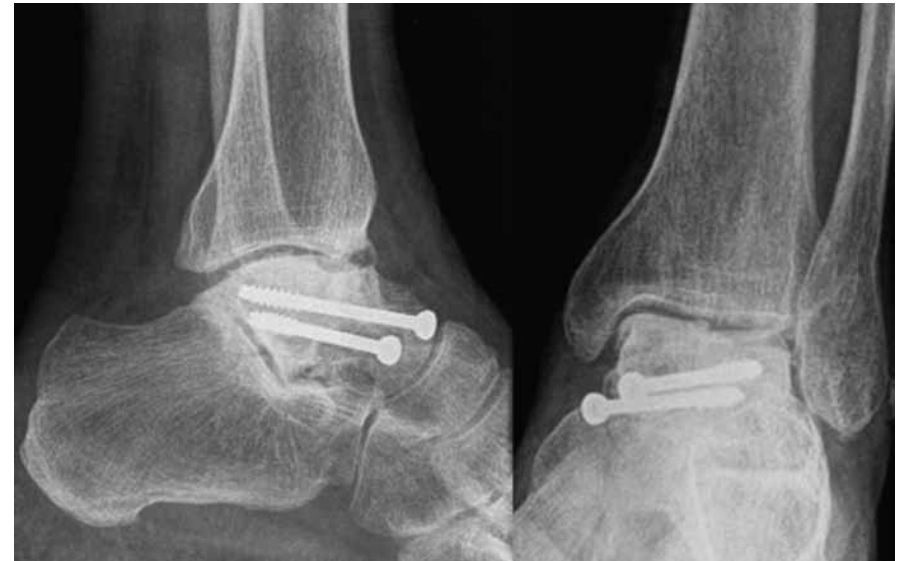

Figure 2 - Preoperative radiographs of the left ankle.

months after the operation), the patient presented an excellent clinical and radiological result. Currently, he is able to walk practically without pain, and without external supports, and he is extremely satisfied with the surgery. Radiological evaluations do not show any migration of components or signs of loosening, as can be seen from Figure 3. The score on the AOFAS hindfoot and ankle scale improved significantly and is now 87 (Table 1).

\section{DISCUSSION}

A high proportion of fractures of the body and neck of the talus lead to late post-traumatic arthrosis, which can cause significant functional disturbance ${ }^{(1-4)}$. After the initial disappointments from the initial designs, total ankle arthroplasty has resurged recently as a valid alternative to arthrodesis for treating ankle $\operatorname{arthrosis}^{(7)}$.

The prosthesis model generally used in our institution is the Salto Total Ankle Prosthesis (Tornier, France), which was designed as an uncemented

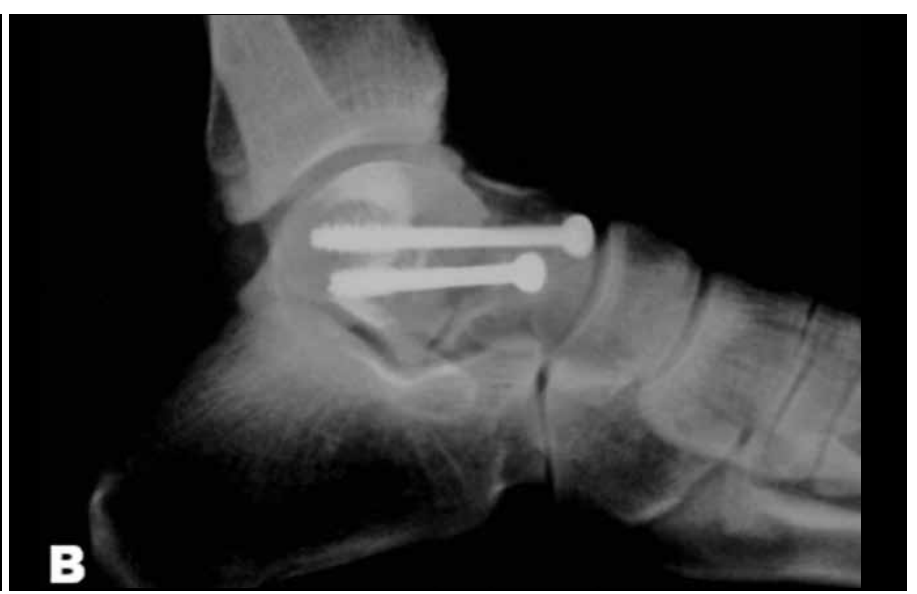

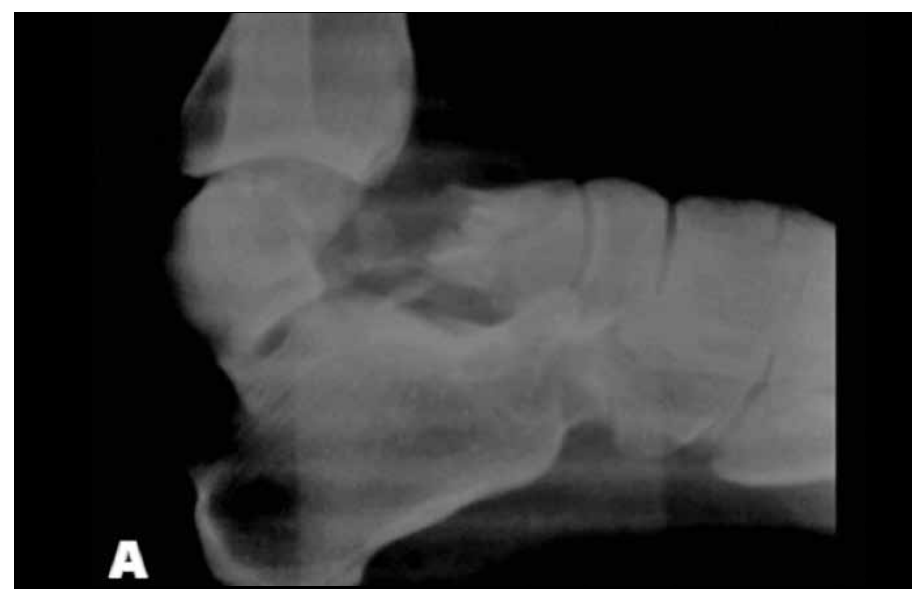

Figure 1 - A) Initial fracture of the talar neck, of Hawkins type II;
B) Control in immediate postoperative period. 


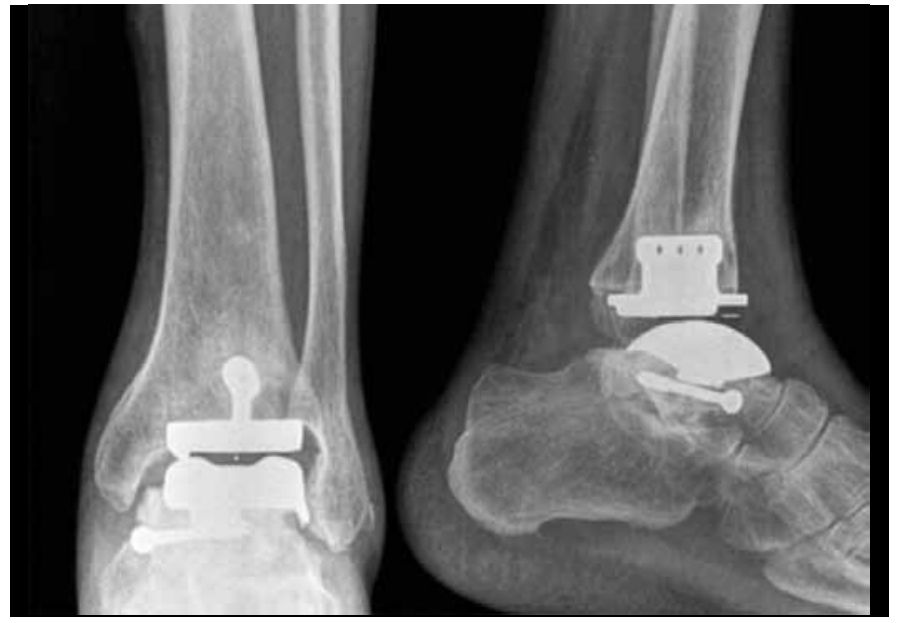

Figure 3 - Radiographs after 12 months of follow-up.

Table 1 - Clinical evolution observed after the treatment that was implemented.

\begin{tabular}{c|c|c}
\hline & $\begin{array}{c}\text { Before the } \\
\text { operation }\end{array}$ & After the operation \\
\hline AOFAS & 19 & 87 \\
\hline Pain & $\begin{array}{c}\text { Severe, almost } \\
\text { always present }\end{array}$ & $\begin{array}{c}\text { Slight and } \\
\text { occasional }\end{array}$ \\
\hline $\begin{array}{c}\text { Sagittal range of motion } \\
\text { (flexion and extension) }\end{array}$ & $12^{\circ}$ & $33^{\circ}$ \\
\hline
\end{tabular}

implant $^{(8)}$. Its porous surface, which is appropriate for interdigitation, is a fundamental trait of all "latest generation" prosthesis models"(6). This characteristic is one of the main reasons why avascular necrosis of the talus has been considered to be a contraindication. The potential for bone integration and uncemented fixation of the component is extremely low in areas of bone necrosis ${ }^{(9)}$. Hintermann ${ }^{(7)}$ even went as far as stating that avascular necrosis affecting more than $25 \%$ of the body of the talus constitutes a relative contraindication, while necrosis affecting more than $50 \%$ constitutes an absolute contraindication for performing total ankle arthroplasty.

\section{REFERÊNCIAS}

1. Lindvall E, Haidukewych G, DiPasquale T, Herscovici D Jr, Sanders R. Open reduction and stable fixation of isolated, displaced talar neck and body fractures. J Bone Joint Surg Am. 2004;86(10):2229-34.

2. Vallier HA, Nork SE, Barei DP, Benirschke SK, Sangeorzan BJ. Talar neck fractures: results and outcomes. J Bone Joint Surg Am. 2004;86(8):1616-24.

3. Schulze W, Richter J, Russe O, Ingelfinger P, Muhr G. Surgical treatment of talus fractures: a retrospective study of 80 cases followed for 1-15 years. Acta Orthop Scand. 2002 ;73(3):344-51.

4. Sousa R, Massada M, Pereira MA, Costa I, Costa e Castro J. Sequelas a longo prazo de fracturas do corpo e colo do astrágalo. Rev Bras Ortop. 2009;44(5):432-6.

5. Rammelt S, Zwipp H. Talar neck and body fractures. Injury. 2009;40(2):120-35.

Rev Bras Ortop. 2011;46(1):94-6
In order to surmount this difficulty, we decided to use bone cement to achieve fixation of the talar component. In addition, we used cement to fill in any bone defects in the talus that we found during the surgery. We decided not to extract the second screw, since it did not interfere with the cut that was made to correctly position the implant. In this way, we avoided further weakening the talus.

One year after the procedure, both the patient and the medical team are satisfied with the result achieved. Future complications, particularly loosening and/ or "sinking" of the component/cement combination in relation to the remains of the talus or even the calcaneus cannot be ruled out. We are aware of the risks involved in this heterodox choice and they were properly explained to and discussed with the patient. Arthrodesis of the ankle was presented as an alternative procedure, or as a rescue procedure in the event of failure of the arthroplasty ${ }^{(10)}$. The patient chose to undergo ankle arthroplasty rather than arthrodesis, accepting that the need for additional surgery may arise in the future. The decision made may be controversial and there is no scientific backing to support it. We do not know of any similar case report in the literature. However, the patient's great willingness to undergo arthroplasty instead of arthrodesis led us to make this risky choice. The extent of the talar necrosis present would be considered to be a contraindication for arthroplasty, given that it not only compromises the integration of the implant but also creates the conditions for progressive collapse of the prosthesis/ cement combination. The good result obtained in this case raises the hypothesis that talar necrosis ought not to be taken to be an absolute contraindication for performing ankle arthroplasty. For this to be possible, cementation will have to be used to fix the talar component and a platform of healthy bone overlying the subtalar will be needed in order to avoid future collapse.

6. Cracchiolo A 3rd, Deorio JK. Design features of current total ankle replacements: implants and instrumentation. J Am Acad Orthop Surg. 2008;16(9):530-40.

7. Hintermann B. Total ankle arthroplasty - historical overview, current concepts and future perspectives. Wien-Austria: Springer-Werlag; 2005.

8. Bonnin M, Judet T, Colombier JA, Buscayret F, Graveleau N, Piriou P. Midterm results of the Salto total ankle prosthesis. Clin Orthop Relat Res. 2004;(424):6-18.

9. Lee KB, Cho SG, Jung ST, Kim MS. Total ankle arthroplasty following revascularization of avascular necrosis of the talar body: two case reports and literature review. Foot Ankle Int. 2008;29(8):852-8.

10. Bullens $P$, de Waal Malefijt $M$, Louwerens JW. Conversion of failed ankle arthroplasty to an arthrodesis. Technique using an arthrodesis nail and a cage filled with morsellized bone graft. Foot Ankle Surg. $2010 ; 16(2): 101-4$. 